\title{
Classification of Turkish Monocultivar (Ayvalık and Memecik cv.) Virgin Olive Oils from North and South Zones of Aegean Region Based on Their Triacyglycerol Profiles
}

\author{
Mümtaz Gökçebağ • Harun Dıraman • \\ Durmuş Özdemir
}

Received: 16 November 2012/Revised: 9 June 2013/Accepted: 16 July 2013/Published online: 20 August 2013 (C) AOCS 2013

\begin{abstract}
In this study, a total of 22 domestic monocultivar (Ayvalık and Memecik cv.) virgin olive oil samples taken from various locations of the Aegean region, the main olive growing zone of Turkey, during two (2001-2002) crop years were classified and characterized by well-known chemometric methods (principal component analysis [PCA] and hierarchical cluster analysis [HCA]) on the basis of their triacylglycerol (TAG) components. The analyses of TAG components (LLL and major fractions LOO, OOO, POO, PLO, SOO, and ECN 42-ECN 50) in the oil samples were carried out according to the HPLC method described in a European Union Commission (EUC) regulation. In all analyzed samples the value of trilinolein (LLL), the least abundant TAG, did not exceed the maximum limit of $0.5 \%$ given by the EUC regulation for different olive oil grades. The ranges of abundant TAG, namely LOO, OOO, POO, PLO, and SOO, were 13.30-16.08, 37.27-46.36, 21.39-23.24, 4.93-7.03, and $4.72-6.00 \%$. The TAG data of Aegean virgin olive oils were similar to those of products from important oliveoil-producing Mediterranean countries was determined. Also, the estimation of major fatty acids (FA) was carried out by using a formula based on TAG data. The PCA
\end{abstract}

M. Gökçebağ

Quality Consultant, Atatürk Organize Sanayi Bölgesi, Çiğli, İzmir, Turkey

H. Diraman ( $₫)$

Department of Food Technologies, Research Station for Olive Culture, 35100 Bornova, İzmir, Turkey

e-mail: harundraman1@hotmail.com

D. Özdemir

Department of Chemistry, Faculty of Science, İzmir Institute of Technology, 35430 Urla, İzmir, Turkey results showed that some TAG components have an important role in the characterization and geographical classification of 22 monocultivar virgin olive oil. The Aegean virgin olive oil samples were successfully classified and discriminated into two main groups as the North and South (growing) subzones or Ayvallk and Memecik olives (cultivars) according to the HCA results based on experimental TAG data and calculated major FA profile.

Keywords Virgin olive oil - Ayvalık $\cdot$ Memecik . Triacylglycerol · Characterization · Classification · Chemometrics · PCA $\cdot$ HCA

\section{Introduction}

Out of the many agricultural products of Turkey, olive oil has a remarkable place. The Aegean region is an important area for olive production with the North and South Aegean regions producing around $60-65 \%$ of the total amount of olive oil manufactured in Turkey. Memecik and Ayvalık are economically major domestic olive cultivars of the Aegean region where their production rates are estimated to be around 40-45\% (south part) and 25-30\% (north part), respectively [1]. In recent years, the production of monocultivar virgin olive oils originated from certain geographic zones (especially Edremit, Ayvalık, Aydın, and Muğla) or cultivars (Ayvallk and Memecik) in Turkey has also increased because of the higher market price and reliable standard of quality. Authentic oils from three zones (Edremit Gulf Olive Oils, Ayvalık Olive Oils, and South Aegean Olive Oils [Memecik]) were certified by the Turkish Patent Institute as PDO (Protected Domination Origin) to verify their production from domestic Ayvalık and Memecik cultivars [2]. 
The authenticity and traceability of monocultivar virgin olive oil are of great importance in terms of consumer protection to prevent fraud and mislabeling. Major and/or minor components such as glyceridic fractions (fatty acids [FA], triacylglycerols [TAG]), sterols, tocopherols, and phenolics were evaluated in combination with chemometric methods to determine the authenticity and traceability of virgin olive oils on the basis of cultivar and geographical origin (growing area). Among the major profiles of olive oil, TAG composition in particular is extremely useful for the characterization and discrimination of an olive cultivar or its geographical location. TAG are main components of olive oils and are formed from a single molecule of glycerol combined with three free fatty acids.

TAG of olive oils have more unique and typical patterns rather than the glycerol molecule which is used to characterize different oil seeds. The TAG profile of an oil provides more information about its structural features and this is remarkably useful for the quality control and origin determination of virgin olive oils. It is widely known that the physical and chemical properties of oils are a strong function of the glyceridic fractions like TAG and FA profiles [3].

Individual contents of some TAG allowed the characterization and classification of olive cultivars using chemometric methods $[3,4]$. In recent years, multivariate data analyses, involving principal component analysis (PCA), hierarchical cluster analysis (HCA), discriminant analysis (DA), and classification analysis (CA), have been used extensively to classify and characterize various foods such as cheeses, vines, and virgin olive oils on the basis of their geographical and production origins. The PCA method, one of the simplest and widely used procedures, is based on variable reduction by linear combination of initial variables defining principal components (PC). It is possible to minimize the set of variables without losing essential initial information [3, 5, 6]. The data obtained from instrumental analysis, gas chromatography (GC) and high-pressure liquid chromatography (HPLC), are evaluated with the sophisticated methods including PCA, HCA, CA, and DA techniques for the characterization and discrimination of virgin olive oil from different locations or cultivars.

A number of investigations based only on TAG profile data in a few defined regions and crop years concerned the characterization and classification of virgin olive oils from various Mediterranean countries [7], e.g., Greek [8], French [9, 10], Spanish [11-14], Tunisian [15, 16], and Turkish [17-19], by using different software programs (SAS, SPSS, SIMCA, Matlab including PCA, HCA, and DA methods).

Turkey is the world's fifth major producer of olive oil (5\%) and shares $11.3 \%$ of the world's exports [1]. There are a few studies [17-19] of the characterization and classification of monocultivar (Memecik and Ayvalı) olive oils produced and marketed in Turkey. The object of this study was to characterize and classify the oils of the predominant olive cultivars Ayvalık and Memecik in the Aegean region by an official HPLC procedure on the basis of the TAG profile, to determine a reliable indicator for discrimination and classification of PDO oils.

\section{Materials and Methods}

Sampling of Monocultivar Aegean Virgin Olive Oils

Twenty-two virgin olive oils produced by three-phase continuous oil extraction of domestic olive cultivars ( $A y$ valik and Memecik) grown in different locations of the Aegean region, Turkey, for 2001-2002 crop years were analyzed in this study (Table 1). Olives (Ayvalık and Memecik) collected from various orchards in the Aegean region were used. Oil samples were divided into two subgroups/zones (North and South) based on olive cultivation (Ayvalık and Memecik) according to the following geographical zones of the Aegean region of Turkey:

1. The North Aegean subgroup or Ayvallk cultivar zone: This zone contains the Ayvalık olive cultivar, widely grown in locations (Havran, Edremit, Ayvalık, Burhaniye, and Altınova) around the Edremit Gulf at Balikesir province, and also there is this cultivar in the Ezine district of Çanakkale province and the Dikili and Menemen districts of Izmir province. Ayvallk cultivar is locally grown in the Akhisar district of Manisa province (Fig. 1). Local Turkish names of Ayvallk olive cultivar are Edremit, Edremit Yă̆lık, Şakran, Midilli, and Ada Zeytini. The center of origin of the Ayvalık cultivar is the Ayvalık district inside the Edremit Gulf [20].

2. The South Aegean subgroup or Memecik cultivar zone: Memecik is the main olive cultivar of this subgroup. This cultivar is grown at locations (Kuşadası, Söke, Germencik, Ortaklar, Aydın, Köşk, Sultanhisar) in the Aydin province. Muğla province (Milas) and some districts of Izmir province (Kemalpaşa, Selçuk, Şirince, Tire, and Bayındır) (Fig. 1). Memecik olive cultivar is known locally as Taş arası, Aşıyeli, Gülümbe, Şehir, and Yă̆lık; it originates from the Milas (Muğla) district in this subgroup [20].

A map of olive growing zones in the Aegean region of Turkey is given in Fig. 1. Table 1 lists the production locations of the olive oil samples along with the corresponding coding of oil samples and TAG profile.

All oil samples were extracted between November and December under industrial conditions in a olive oil plant in Çiğli, Izmir, Turkey. Sample aliquots were removed from each of three bottles from the same extraction for each sample. For each oil sample, $1,500 \mathrm{~mL}$ was divided into 
Table 1 Triacylglycerol and fatty acid profiles and production locations of olive oils sampled along with the corresponding coding

\begin{tabular}{|c|c|c|c|c|c|c|}
\hline \multirow{2}{*}{$\frac{\text { Locations }}{\text { North Aegean zone }}$} & \multirow[t]{2}{*}{ Code } & \multirow[t]{2}{*}{ Cultivars } & \multirow[t]{2}{*}{ TAG } & \multirow[t]{2}{*}{ Code } & \multicolumn{2}{|l|}{ Fatty acids } \\
\hline & & & & & & \\
\hline Ezine & $\mathrm{EZ}$ & Ayvalık & LLL & L1 & Palmitic & $\mathrm{P}$ \\
\hline Havran & $\mathrm{HV}$ & Ayvalık & OLnL & $\mathrm{O} 1$ & Stearic & $\mathrm{S}$ \\
\hline Edremit & ED & Ayvalık & LOL & $\mathrm{L} 2$ & Oleic & $\mathrm{O}$ \\
\hline Ayvalık & AV & Ayvalık & OLnO & $\mathrm{O} 2$ & Linoleic & $\mathrm{L}$ \\
\hline Burhaniye & $\mathrm{BR}$ & Ayvalık & PLL & P1 & Linolenic & LN \\
\hline Altınova & $\mathrm{AL}$ & Ayvalık & POLn & $\mathrm{P} 2$ & SFA & SF \\
\hline Dikili & DK & Ayvalık & LOO & L3 & MUFA & MF \\
\hline Akhisar & $\mathrm{AK}$ & Ayvalık & POL & P3 & PUFA & $\mathrm{PF}$ \\
\hline Menemen & MN & Ayvalık & PLP & $\mathrm{P} 4$ & PUFA/SFA & $\mathrm{PF}-\mathrm{SF}$ \\
\hline South Aegean & & & OOO & $\mathrm{O} 3$ & & \\
\hline Kemalpaşa & KM & Memecik & $\mathrm{OPO}$ & $\mathrm{O} 4$ & Palmitic/linoleic & $\mathrm{P}-\mathrm{L}$ \\
\hline Selçuk & SL & Memecik & POP & $\mathrm{P} 4$ & Linoleic/linolenic & $\mathrm{L}-\mathrm{LN}$ \\
\hline Şirince & SR & Memecik & PPP & P5 & Iodine value & IV \\
\hline Tire & TR & Memecik & OSO & O5 & Oxidative susceptibility & OS \\
\hline Bayındır & BY & Memecik & POS & P6 & Unsaturated/saturated & UF-SF \\
\hline Kuşadası & KS & Memecik & $\mathrm{ECN} 42$ & E1 & & \\
\hline Söke & SK & Memecik & $\mathrm{ECN} 44$ & E2 & & \\
\hline Aydin & AY & Memecik & ECN 46 & E3 & & \\
\hline Germencik & GR & Memecik & $\mathrm{ECN} 48$ & E4 & & \\
\hline Ortaklar & OR & Memecik & ECN 50 & E5 & & \\
\hline Köşk & KK & Memecik & POL/OOO & P7 & & \\
\hline Sultanhisar & $\mathrm{SH}$ & Memecik & LLL/ECN42 & L4 & & \\
\hline Milas & ML & Ayvalık & PLL/LOL & P8 & & \\
\hline ECN values & & & & & & \\
\hline ECN 42 & \multicolumn{6}{|c|}{ LLL + LOLn + POLL + PLLn } \\
\hline $\mathrm{ECN} 44$ & \multicolumn{6}{|c|}{$\mathrm{OLL}+\mathrm{OLnO}+\mathrm{PLL}+\mathrm{POLn}$} \\
\hline ECN 46 & \multicolumn{6}{|c|}{$\mathrm{LOO}+\mathrm{PLnP}+\mathrm{PoOO}+\mathrm{PLO}+\mathrm{SLL}+\mathrm{PoOP}+\mathrm{PLP}$} \\
\hline $\mathrm{ECN} 48$ & \multicolumn{6}{|c|}{$\mathrm{OOO}+\mathrm{SLO}+\mathrm{POO}+\mathrm{POP}+\mathrm{PPP}$} \\
\hline ECN 50 & \multicolumn{6}{|c|}{$\mathrm{SOO}+\mathrm{POS}$} \\
\hline
\end{tabular}

three dark glass bottles, $500 \mathrm{~mL}$ per bottle, and refrigerated at $4{ }^{\circ} \mathrm{C}$ until they were analyzed.

The processing steps of the so-called three-phase continuous centrifugation system (the most popular extraction system in Turkey) are generally as follows [21]: (1) olives (350 kg), (2) leaf removal and washing, (3) crushing (by metallic hammer mills) (4) malaxation (mixing) (30-40 min at $40{ }^{\circ} \mathrm{C}$ with water addition), (5) centrifugal extraction (decanter 3,500-4,000 rpm), (6) oily must (20-22\%), (7) vertical centrifugal separation of oily must (5,500-6,500 rpm), (8) pomace (more than $45 \%$ moisture), (9) vegetable water (olive juice).

\section{TAG Composition Determination}

The analysis of the TAG profile in olive oil samples was performed according to the official HPLC method described in the European Union Commission regulation EEC/2568/ 91 [22]. All the analyses were carried out in a Hewlett Packard 1100 HPLC system (Palo Alto, CA, USA) consisting of a degasser, quaternary pump, manual six-way injection valve, refractive index detector, and Chemistation software (HP 3365) package program for instrument control and data acquisition. The results were expressed as a percentage of total TAG. The column was a LiChrospher 100 RP-18 HPLC column (Germany) $(5 \mu \mathrm{m} \times 250 \times 4 \mathrm{~mm}$ i.d., temperature $\left.35^{\circ} \mathrm{C}\right)$. A loop of $100 \mu \mathrm{L}$ capacity was used in which $1.0 \mu \mathrm{L}$ sample was injected. The mobile phase was acetone/acetonitrile (63.6:36.4) delivered isocratically at a flow rate of $1.00 \mathrm{~mL} / \mathrm{min}$ under nebulizer gas pressure 2.00 bar for $45 \mathrm{~min}$. Nineteen TAG identifications were determined by comparing our results to data in the literature $[9,10]$ and by calculating the equivalent carbon numbers (ECN). The TAG are designated by letters corresponding to abbreviated names of fatty acid carbon 


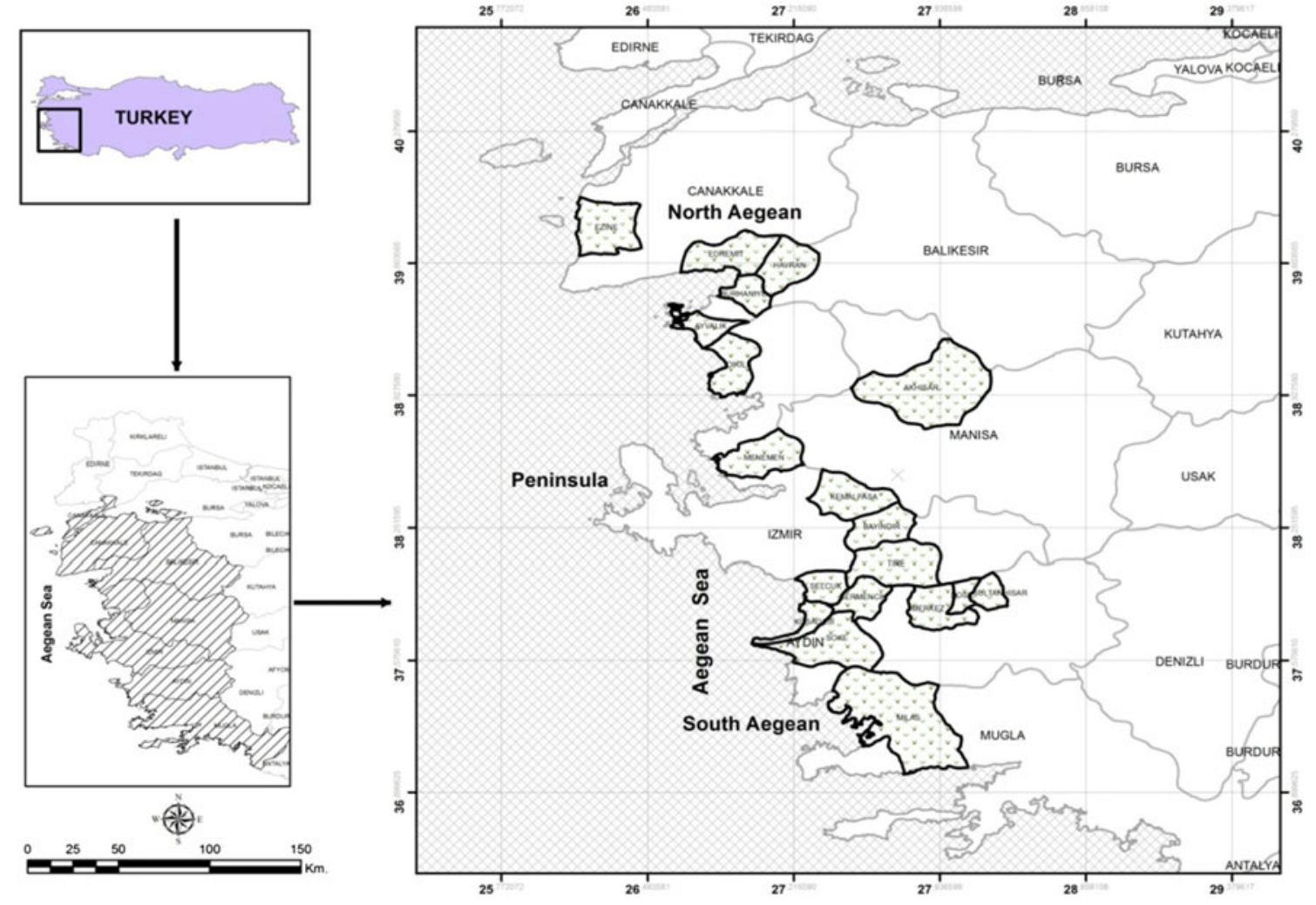

Fig. 1 Locations of virgin olive oil samples collected in the Aegean region of Turkey

chains that are attached to the glycerol. The abbreviations of fatty acids are palmitoyl (P), palmitoleyl (Po), stearoyl (S), oleoyl (O), linoleoyl (L), and linolenyl (Ln).

The major fatty acid (FA) profile of the oil samples was calculated by means of the developed formula based on TGA components [23]. In addition some parameters including saturated fatty acids (SFA), monounsaturated fatty acids (MUFA), polyunsaturated fatty acids (PUFA), oleic/linoleic (O-L), linoleic/linolenic (L-LN), palmitic/ linoleic ( $\mathrm{P}-\mathrm{L})$, iodine values (IV), oxidative susceptibility (OS), and total unsaturated fatty acids (UFA)/total saturated fatty acids (SFA) from calculated data were determined.

Iodine values (IV) were calculated from fatty acid percentages by using the following formula [24]: IV = $(\%$ monounsaturated fatty acids $\times 0.860)+(\%$ linoleic $\times$ $1.732)+(\%$ linolenic $\times 2.616)$.

Oxidative susceptibility (OS) was estimated from fatty acid values by using the formula given by Cert et al. [25]: oxidative susceptibility $(\mathrm{OS})=\mathrm{MUFA}+(45 \times$ linoleic $)+$ $(100 \times$ linolenic $)$.

\section{Chemometric Analysis}

Characterization and classification of Aegean monocultivar (Ayvalık and Memecik cv.) virgin olive oils were carried out using chemometric methods, PCA (Ward's algorithmic method) and HCA (Euclidian distance). The data obtained in "*spc" format was sampled by the Origin 8.0 (Northampton, USA) program and multivariate analysis was performed using Matlab 7.5.0 (R2007b). All data and autoscaled variables were normalized prior to the chemometric analysis [26].

\section{Results and Discussion}

\section{TAG Profile}

TAG represent about $96 \%$ of the virgin olive oil composition. Nine TAG were identified, and their content (expressed as percentages of total TAG) exhibited some variations among the different monocultivar oils. OOL, POL, OOO, and POO accounted for more than $96 \%$ of the total TAG, whereas PLL, OLL, POLn, PPO, and SOO were present in low percentages. The Aegean virgin olive oil samples from Ayvalık and Memecik olives are characterized by four main TAG, namely OOO, POO, LOO, and PLO, and three secondary TAG, namely LOL, POP, and SOO. TAG data are a valuable quantitative measure of the quality and purity of vegetable oils and are of great importance as an authenticity indicator of geographic 


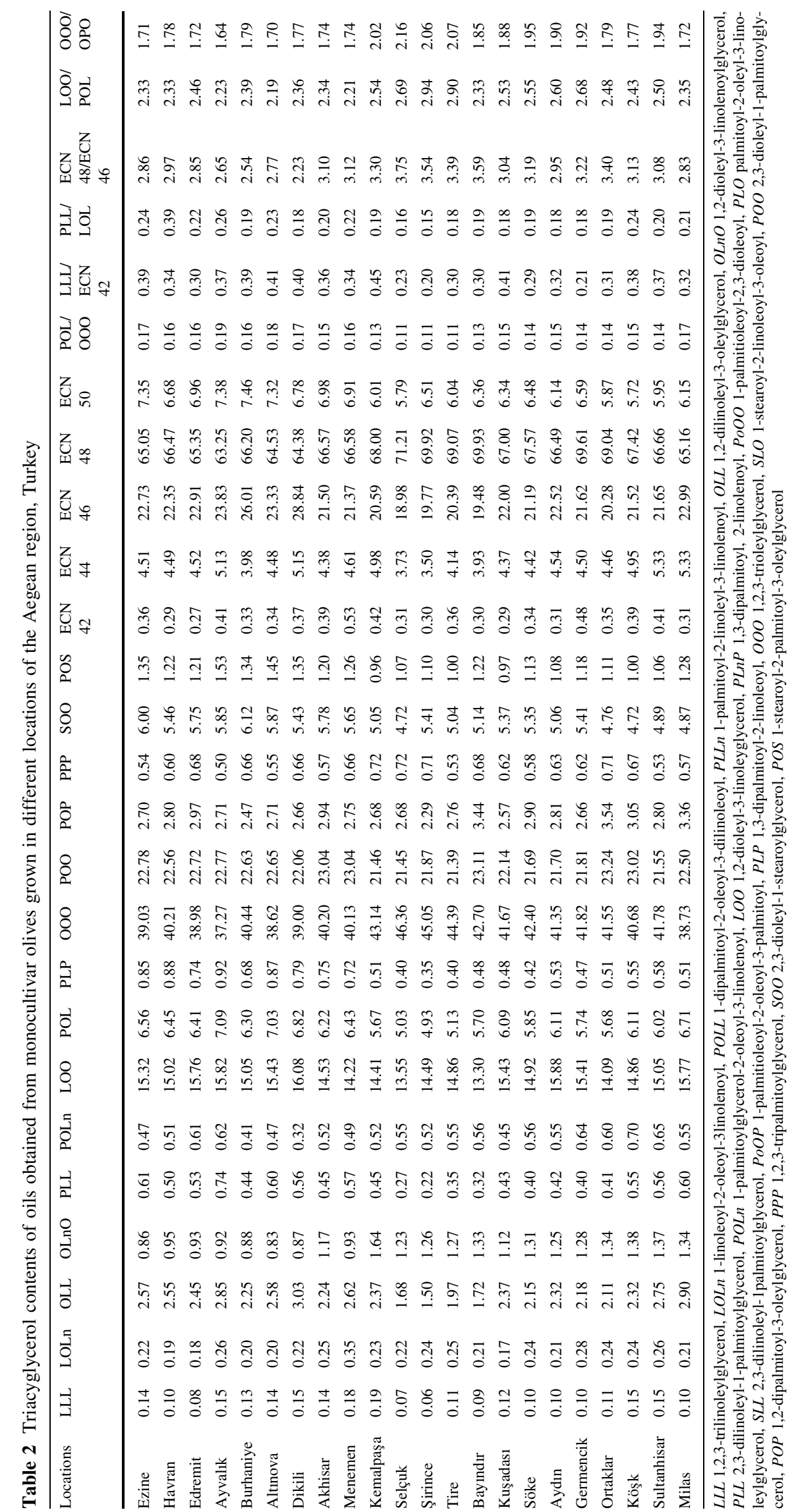


origin/monocultivar of virgin olive oils [3, 5-7, 27]. As shown in Table 2, TAG were detected in the Aegean virgin olive oil samples produced from important domestic olive cultivars (Ayvalık and Memecik cv.) in different locations. The main TAG peaks in the Aegean virgin olive oil samples produced from monocultivar olives (Ayvallk and Memecik cv.) were 1,2,3-trioleoylglycerol or triolein (OOO), 1,3-dioleoyl-2-linoleoylglycerol (LOO), 1-stearoyl-2-linoleoyl-3-oleoylglycerol + 2,3-dioleyl-1-palmi-

toylglycerol (SLO + POO), 1-palmitoleoyl-2-oleoyl-3linoleoylglycerol + 2,3-dilinoleoyl-1-stearoylglycerol (PLO + SLL), and 2,3-dioleyl-1-stearoylglycerol (SOO); these accounted for approximately $85 \%$ of the total peak areas in the chromatogram.

Levels of LLL (trilinoein), an important minor TAG, in the North and South Aegean oil samples were 0.08-0.15\% and $0.09-0.19 \%$, respectively. The ECN 42 fraction (LLL, LOLn [1-linoleoyl-2-oleoyl-3-linolenoyl] and PLLn [1palmitoyl-2-linoleyl-3-linolenoyl]) in the oils samples according to the North and South Aegean zones was determined to be $0.27-0.41 \%$ and $0.29-0.48 \%$, respectively. In general, all the oil samples had low levels of
LLL, in no case exceeding $0.5 \%$. The levels of oils from the Ayvalık cultivar (North Aegean origin) were more limited, while the LLL and ECN 42 levels of oils of the Memecik cultivar (South Aegean origin) had a wide range (Table 2). The level of LLL in all oil samples did not exceed the maximum limit of $0.5 \%$ determined according to the EUC regulation for different olive grades [22]. Authentic virgin olive oils do not have an LLL peak over $0.5 \%$. The presence of a high OOO level in an olive oil, in inverse proportion to LLL, constitutes a favorable authenticity indicator for the most common European oils.

TAG composition shows great variability between oils, as previously described for fatty acids. For example, the OOO (triolein), the main TAG in all olive cultivars, varies between 37.27 and $40.21 \%$ for North Aegean (Ayvalık cultivar) and 38.73 and $46.36 \%$ for South Agean (Memecik cultivar). The OOO levels of North Aegan oil samples were lower than those of South Aegean samples. The presence of a high OOO level in olive oil constitutes a favorable authenticity indicator $[3,5,27]$. These data are consistent with the high proportion of oleic acid in olive oils.

Table 3 Major fatty acid contents calculated on the basis of triacylglycerol data of oils obtained from monocultivar olives grown in different locations of the Aegean region, Turkey

\begin{tabular}{|c|c|c|c|c|c|c|c|c|c|c|c|c|c|c|c|}
\hline Locations & $\mathrm{P}$ & $\mathrm{S}$ & $\mathrm{O}$ & $\mathrm{L}$ & $\mathrm{LN}$ & SF & MF & $\mathrm{PF}$ & $\mathrm{PF}-\mathrm{SF}$ & $\mathrm{O}-\mathrm{L}$ & $\mathrm{P}-\mathrm{L}$ & L-LN & IV & OS & UF-SF \\
\hline $\mathrm{EZ}$ & 13.5 & 2.45 & 73.63 & 9.77 & 0.66 & 15.95 & 73.63 & 10.43 & 0.65 & 7.54 & 1.38 & 14.80 & 81.97 & 579.28 & 5.27 \\
\hline HV & 13.47 & 2.23 & 74.11 & 9.55 & 0.69 & 15.70 & 74.11 & 10.24 & 0.65 & 7.76 & 1.41 & 13.84 & 82.08 & 572.86 & 5.37 \\
\hline ED & 13.65 & 2.32 & 73.7 & 9.68 & 0.71 & 15.97 & 73.70 & 10.39 & 0.65 & 7.61 & 1.41 & 13.63 & 82.01 & 580.30 & 5.27 \\
\hline AV & 13.84 & 2.46 & 72.53 & 10.42 & 0.74 & 16.30 & 72.53 & 11.16 & 0.68 & 6.96 & 1.33 & 14.08 & 82.36 & 615.43 & 5.13 \\
\hline $\mathrm{BR}$ & 13.22 & 2.44 & 74.5 & 9.20 & 0.64 & 15.66 & 74.50 & 9.84 & 0.63 & 8.10 & 1.44 & 14.38 & 81.68 & 552.50 & 5.39 \\
\hline $\mathrm{AL}$ & 13.67 & 2.44 & 73.29 & 9.96 & 0.64 & 16.11 & 73.29 & 10.60 & 0.66 & 7.36 & 1.37 & 15.56 & 81.95 & 585.49 & 5.21 \\
\hline DK & 13.33 & 2.26 & 73.43 & 10.36 & 0.61 & 15.59 & 73.43 & 10.97 & 0.70 & 7.09 & 1.29 & 16.98 & 82.69 & 600.63 & 5.41 \\
\hline $\mathrm{AK}$ & 13.51 & 2.33 & 74.34 & 9.04 & 0.79 & 15.84 & 74.34 & 9.83 & 0.62 & 8.22 & 1.49 & 11.44 & 81.66 & 560.14 & 5.31 \\
\hline $\mathrm{MN}$ & 13.57 & 2.30 & 73.99 & 9.37 & 0.73 & 15.87 & 73.99 & 10.70 & 0.64 & 7.90 & 1.45 & 12.84 & 81.77 & 568.64 & 5.30 \\
\hline KM & 12.53 & 2.00 & 75.66 & 8.82 & 0.94 & 14.53 & 75.66 & 9.76 & 0.67 & 8.58 & 1.42 & 9.38 & 82.80 & 566.57 & 5.88 \\
\hline SL & 12.23 & 1.93 & 77.4 & 7.70 & 0.81 & 14.16 & 77.40 & 8.51 & 0.60 & 10.05 & 1.59 & 9.51 & 82.02 & 504.90 & 6.07 \\
\hline SR & 12.02 & 2.17 & 77.26 & 7.82 & 0.81 & 14.19 & 77.26 & 8.63 & 0.61 & 9.88 & 1.54 & 9.65 & 82.11 & 510.16 & 6.05 \\
\hline TR & 12.11 & 2.01 & 76.65 & 8.43 & 0.83 & 14.12 & 76.65 & 9.26 & 0.66 & 9.09 & 1.44 & 10.16 & 82.69 & 539.00 & 6.08 \\
\hline BY & 13.60 & 2.12 & 75.57 & 7.92 & 0.84 & 15.72 & 75.57 & 8.76 & 0.56 & 9.54 & 1.72 & 9.43 & 80.91 & 515.97 & 5.36 \\
\hline $\mathrm{KS}$ & 12.68 & 2.11 & 75.25 & 9.26 & 0.72 & 14.79 & 75.25 & 9.98 & 0.67 & 8.13 & 1.37 & 12.86 & 82.64 & 563.95 & 5.76 \\
\hline SK & 12.67 & 2.16 & 75.52 & 8.84 & 0.84 & 14.83 & 75.52 & 9.68 & 0.65 & 8.54 & 1.43 & 10.52 & 82.46 & 557.32 & 5.75 \\
\hline AY & 12.81 & 2.05 & 74.97 & 9.40 & 0.81 & 14.86 & 74.97 & 10.21 & 0.69 & 7.98 & 1.36 & 11.60 & 82.87 & 578.97 & 5.73 \\
\hline GR & 12.63 & 2.20 & 75.32 & 9.02 & 0.87 & 14.83 & 75.32 & 9.89 & 0.67 & 8.35 & 1.40 & 10.37 & 82.67 & 568.22 & 5.75 \\
\hline OR & 13.76 & 1.96 & 74.93 & 8.52 & 0.87 & 15.72 & 74.93 & 9.39 & 0.60 & 8.79 & 1.62 & 9.79 & 81.47 & 545.33 & 5.36 \\
\hline KK & 13.53 & 1.91 & 74.47 & 9.17 & 0.91 & 15.44 & 74.47 & 10.08 & 0.65 & 8.12 & 1.48 & 10.08 & 82.31 & 578.12 & 5.48 \\
\hline SH & 12.73 & 1.98 & 74.87 & 9.51 & 0.90 & 14.71 & 74.87 & 10.41 & 0.71 & 7.87 & 1.34 & 10.57 & 83.21 & 592.82 & 5.80 \\
\hline ML & 13.70 & 2.05 & 73.41 & 10.07 & 0.84 & 15.75 & 73.41 & 10.91 & 0.69 & 7.29 & 1.36 & 11.99 & 82.77 & 610.56 & 5.35 \\
\hline
\end{tabular}

$P$ palmitic, $S$ stearic, $O$ oleic, $L$ linoleic, $L N$ linolenic, $S F$ saturated fatty acids (SFA), $M F$ monounsaturated fatty acid (MUFA), $P F$ polyunsaturated fatty acid (PUFA), $P F-S F$ PUFA/SFA, $O-L$ oleic/linoleic, $P-L$ palmitic/linoleic, $L-L N$ linoleic-linolenic, $I V$ iodine value, $O S$ oxidative susceptibility, $U F-S F$ total unsaturated FA/SFA 
The results of five experimental equivalent carbon number analyses from ECN 42 to ECN 50 for Aegean virgin olive oils samples produced from domestic olive cultivars (Ayvallk and Memecik) in different locations are also shown in Table 2. Virgin olive oil is essentially characterized by four main peaks with ECN of 44, 46, 48, and 50 based on experimental equivalent carbon numbers of TAG [22]. In descending order, the experimental value of ECN in the oil samples are ECN 48 (between 63.25 and $71.21 \%$ ), ECN 46 (between 18.98 and $28.84 \%$ ), ECN 50 (between 5.72 and $7.46 \%$ ), and ECN 44 (3.50 and $5.33 \%)$. Differences among of ECN values of olive oil samples were observed. Compared with North Aegean oil samples (Ayvalık cultivar), the ECN 46 and 50 values of South Aegean oils (Memecik cultivar) were low. Also, the ECN 48 values found in South Aegean oils were higher than those in North Aegean samples (Table 2).

Although analyses conditions in the mobile phase were different, the main TAG values (OOO, POO, LOO, PLO, and LLL) and related parameters (ECN 42-ECN 50) are comparable to those of the most common Greek [8], French [9, 10], Spanish [11-14], and Turkish [17, 18] oils, but have significant differences compared with Tunisian oils $[15,16]$ and Turkish sample [19]—except similar POO values.

The LLL/ECN42, PLO/OOO, PLL/LOL, ECN48/ ECN46 [27], LOO/PLO and OOO/POO [28], proposed important chemical parameters based on the TAG profile for detecting the presence of seed oils in olive oil, are shown in Table 2. These data may contribute to studies about the detection of adulteration in virgin olive oils. These findings on TAG are generally in accordance with previously studies [28, 29].

There were differences among the data of TAG profiles of the Aegean monocultivar (Ayvalık and Memecik cv.) virgin oil samples from different locations. The obtained results showed that TAG composition was the most useful parameter for discriminating between cultivars or their origins. Different factors such as the nature of the cultivar [11], soil characteristics, climatic conditions (humidity and rainfall), geographic position (altitude, latitude, distance from the sea), olive maturity, and irrigation $[8,12]$ may affect the variation in TAG profiles of Aegean virgin olive oils.

Major Fatty Acid Profile Estimated on the Basis of TAG

Five major FA (palmitic, stearic, oleic, linoleic, and linolenic) were estimated (calculated) on the basis of TAG data of the Aegean virgin olive oil samples produced from Ayvalık and Memecik olives. FA composition like TAG data is a considerable source of the quality and purity of virgin olive oils and can give information about the geographic origin or cultivar of monocultivar olive oils as an authenticity indicator $[3,5-7,13,21,27]$. As shown in Table 3, FA were calculated in virgin olive oil samples obtained from major olive cultivars (Ayvalık and Memecik $\mathrm{cv}$.) in two zones of the Aegean region.

The FA, mainly major fatty acids, composition estimated on the basis of TAG gave considerable variability among oil samples of Ayvalık and Memecik cv. olives grown in two zones of the Aegean region. The ranges of major FA (oleic, palmitic, linoleic, stearic, and linolenic) were $72.53-77.40 \%, \quad 12.11-13.84 \%, \quad 7.7-10.42 \%$. $1.91-2.45 \%$, and $0.61-0.94 \%$, respectively. The oleic levels of North Aegan oil samples (Ayvallk cultivar) (72.53-74.34 \%) were lower than those in South Aegean samples (Memecik cultivar) (73.41-77.40\%), whereas the concentrations of linoleic of North Aegan oil samples (9.04-10.42\%) were higher than those in South Aegean samples (7.7-10.07\%). The range of linolenic acid levels (0.61-0.94\%) of Aegean virgin olive oil samples produced from Ayvalık and Memecik cultivars was below the maximum value fixed by the IOOC $(1.0 \%)$. On the basis of their fatty acid compositions, Aegean virgin olive oil samples from Ayvalık and Memecik cultivars are characterized by low linoleic and palmitic oils and high oleic levels. These oil types originated from the North Mediterranean, e.g., Spanish, Italian, Greek, and Turkish products [21].

The changes of oleic/linoleic $(\mathrm{O}-\mathrm{L})$ ratio (minimum value of 7), which are of great importance for the estimation of oxidative stability, were $6.96-8.10$ for North Aegan oil samples (Ayvalık cultivar) and 7.29-10.05 for South Aegean samples (Memecik cultivar). For the North Aegean oils samples including Ayvalık cultivars the ratio was lower because of the higher linoleic acid level (9.2-10.42\%) (Table 2). The nutritional (linoleic/linolenic or $\omega 6 / \omega 3$ ) fatty acid ratios of the oil samples (a value considered to be optimal at 12) were 11.44-16.98 for North Aegan oil samples (Ayvallk cultivar) and 9.38-12.86 for South Aegean samples (Memecik cultivar). In addition in empirical results have shown that the ratio of linoleic/linolenic correlates with the bitterness and green perception of oils due to the contribution of volatile compounds to virgin olive oil flavor, e.g., the lower the ratio is the higher the bitterness [5].

The IV were calculated according to their fatty acid compositions (Table 3). There is no specification in the EU and IOC regulations about IV. The IV of Tunisian oil [15, 16] was higher than those of our results. The saturated (SFA) and unsaturated (MUFA and PUFA) levels of olive oils affected the IV. Oxidative susceptibility estimated on the basis of the FA profile represents the theoretical stability of the oil samples. It was observed that the OS value 

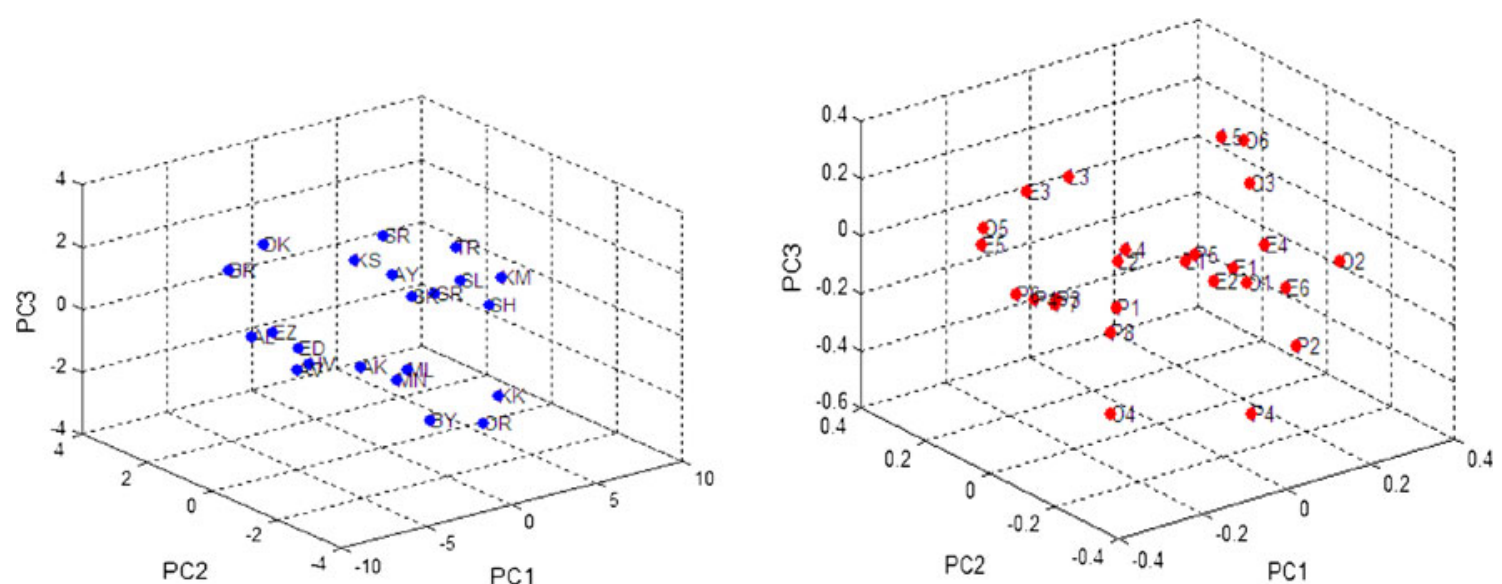

Fig. 2 Scores (left) and loadings (right) plot of first three PC (PC1, PC2, and PC3) for the Turkish virgin olive oil samples from Aegean region based on their triacylglycerol profiles

of oil samples increased with high linoleic acid content more than MUFA. Also, OS values of South Aegean samples (Memecik cultivar) (504.9-610.6) were lower than those of North Aegan oil samples (Ayvallk cultivar) (552.50-615.43) (Table 3). Similar findings on the OS parameter was reported by Cert et al. [25]. The alterations in FA composition of the Aegean monocultivar (Ayvalık and Memecik cv.) virgin oil samples may originate from latitude, climate, olive cultivar, and/or stage of fruit maturity during harvest like the TAG profile $[8,12,15,21$, 27].

\section{Chemometric Analysis}

The TAG components played a role in the characterization of monocultivar oils of olive cultivars in different geographical locations of the Aegean region, Turkey (Figs. 2, 3 ). The chemometric analysis (PC1, PC2, and PC3) showed that OSO and ECN 50 were responsible for the classification of Burhaniye (BR, Ayvalık cultivar). The Edremit (ED), Havran (HV), and Ayvalık (AV) (Ayvalık cultivar) samples were characterized by their POP and POL/LOL levels, whereas Ezine (EZ) and Altınova (AL) samples including Ayvalık cultivars were characterized by POS. Also, PLL and PLL/LOL were useful for the classification of Akhisar (AK) sample produced from Ayvalık cultivar, whereas Dikili (DK) sample was identified according to ECN 46. Tire (TR), Selçuk (SL), and Kemalpaşa (KM) samples from Memecik cultivar were characterized by OOO, whereas Şirince (SR) sample was identified by LOO/ $\mathrm{POL}$ and OOO/OPO contents. LLL and PPP were useful in the classification of Söke (SK) and Germencik (GR) districts covering the most part of the South Aegean zone growing domestic Memecik olive cultivar, whereas the Sultanhisar (SH) sample was characterized by ECN 48 and ECN 48/ECN 46. The Köşk (KK) sample was identified

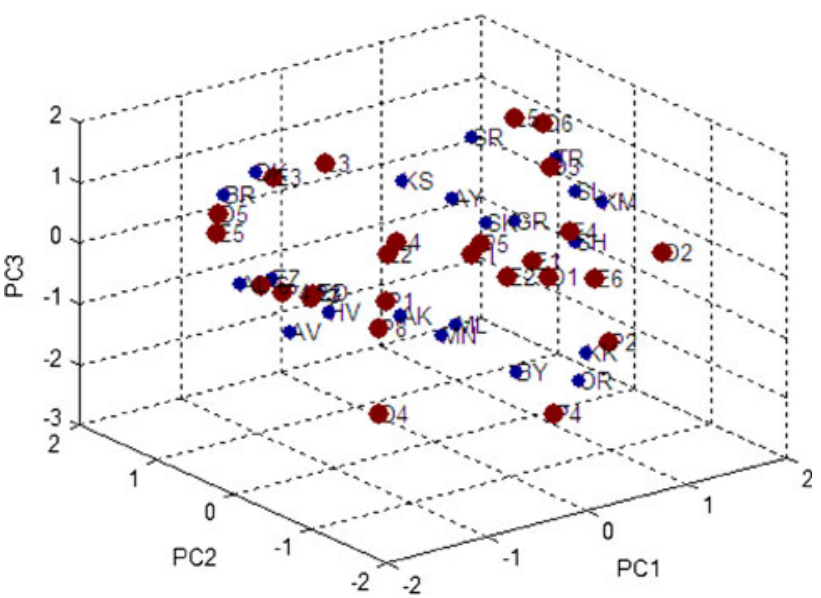

Fig. 3 Biplot of scores (left) and loadings (right) for the first three PC (PC1, PC2 and PC3) for the Turkish virgin olive oil samples from Aegean region based on their triacylglycerol profiles (the first three PC which accounts for $98 \%$ of the variability in the data)

according to its POLn level, whereas the Ortaklar (OR) sample was characterized by POP.

In this study, the Aegean monocultivar (Ayvallk and Memecik cv.) virgin olive oils from different geographic locations were classified by chemometric methods (PCA and HCA). The dendrogram (Fig. 4) based on the HCA results (Euclidian method) of olive oil samples could be divided into main two groups-North Aegean (Ayvallk cultivar) and South Aegean (Memecik Cultivar)—on the basis on their TAG profile (Fig. 4).

As can seen from Fig. 4, group 1 (North Aegean zone including Ayvalık olive cultivar) is made up of three subgroups and they include Ezine (EZ), Altınova (AL), Burhaniye (BR), and Dikili (DK) (subgroup 1); Menemen (MN) and Akhisar (AK) (subgroup 2); and Havran (HV), Edremit (ED), and Milas (ML) (subgroup 3) according to the locations. Group 2 comprised three subgroups covering the 


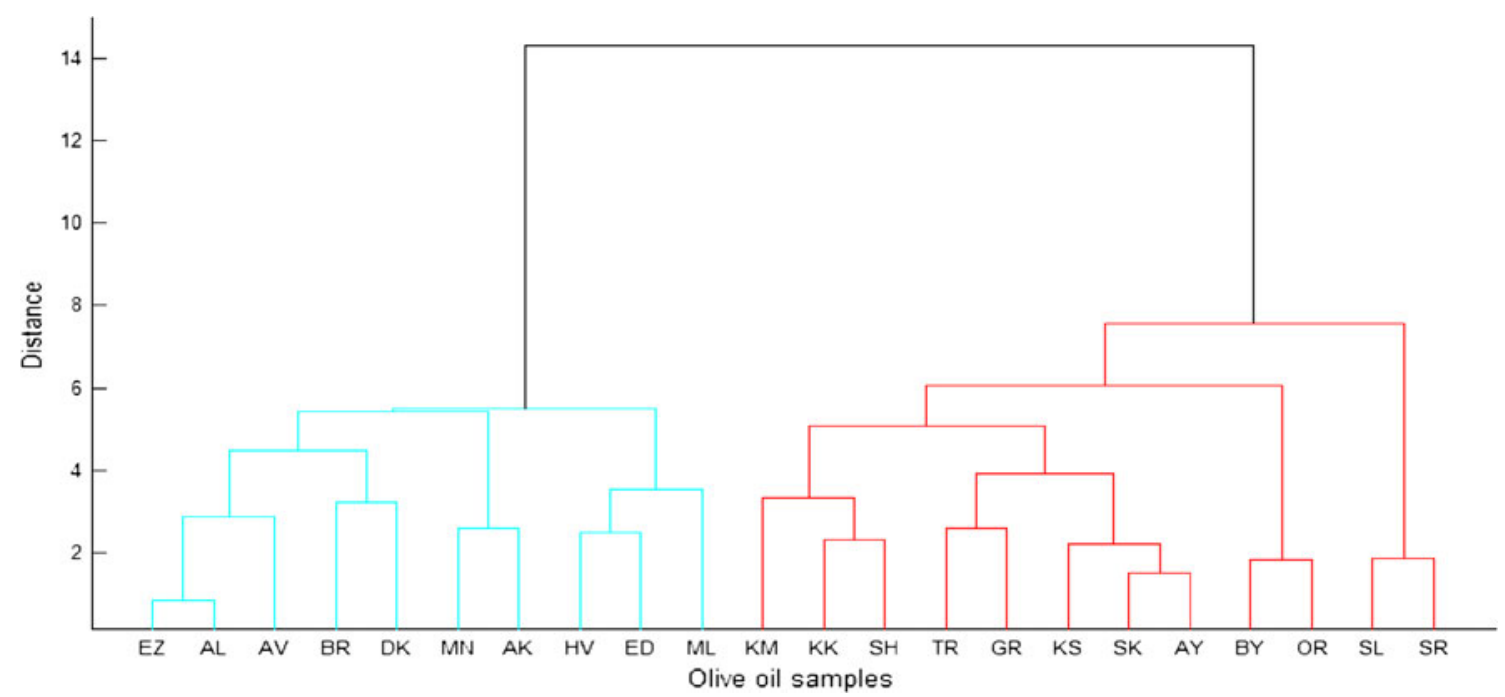

Fig. 4 Dendogram of scores of first three PC (PC1, PC2, PC3) from the hierarchical cluster analysis (HCA) for the Turkish virgin olive oil samples from the Aegean region based on their triacylglycerol profiles (the first three PC account for $98 \%$ of the variability in the data)
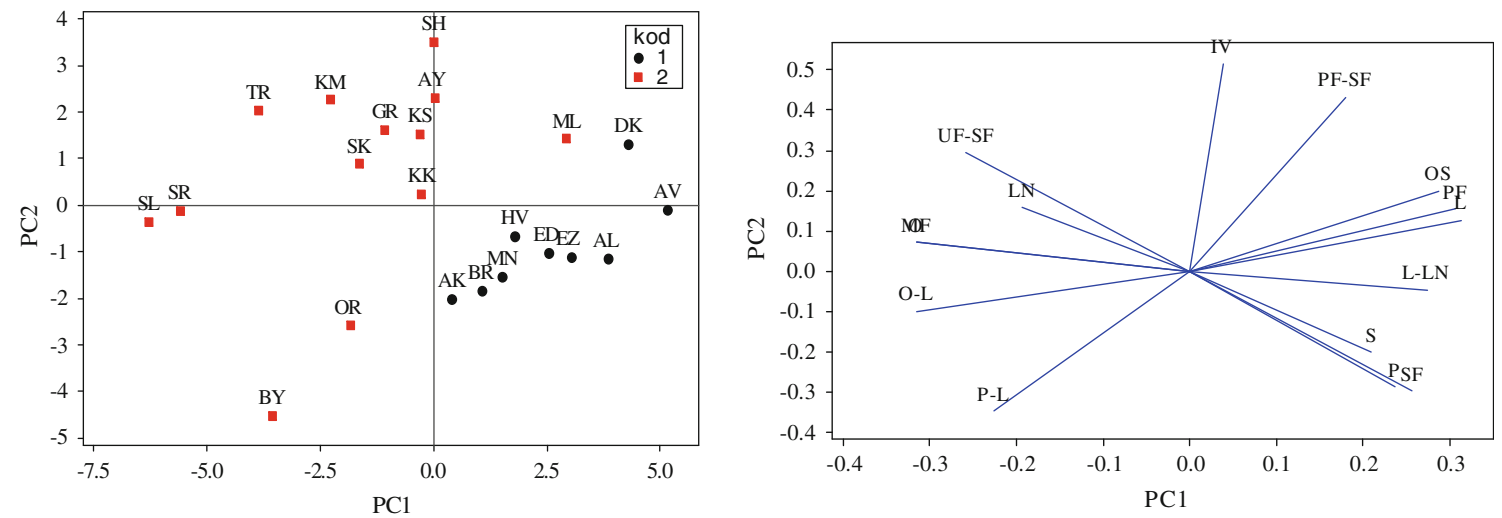

Fig. 5 Scores (left) and loadings (right) plot of first three PC (PC1, PC2, and PC3) for the Turkish virgin olive oil samples from the Aegean region based on their fatty acid profiles

Memecik olive cultivar and includes Kemalpaşa (KM), Köşk (KK), Sultanhisar (SH), Tire (TR), Germencik (GR), Kuşadası (KS), Söke (SK), and Aydın (AY) (subgroup 1); Bayındır (BY) and Ortaklar (OR) (subgroup 2); and Selçuk (SL) and Şirince (ŞR) (subgroup 3).

The chemometric analysis (PC1, PC2, and PC3) regarding FA profile estimated on the basis of TAG data exhibited some considerable indications about the characterization and classification of Aegean monocultivar virgin olive oils (Figs. 5, 6). The Tire (TR), Kemal Paşa (KM), Köşk (KK), and Söke (SK) (Memecik cultivar) samples were discriminative in unsaturated FA/saturated FA (UF$\mathrm{SF}$ ) and linolenic (LN), whereas Sultanhisar (SH), Aydın (AY), Germencik (GR), and Kuşadası (KS) samples from Memecik olive cultivar were characterized by IV. Oleic acid, oleic/linoleic (O-L), and MUFA were responsible for the classification of Selçuk (SL) and Şirince (ŞR) oil samples (Memecik). Oxidative susceptibility (OS), PUFA, and linoleic acid (L) played a role in the characterization of Milas (ML) (Memecik cv.) and Dikili (DK) (Ayvalık cv.) samples, whereas Ayvalık oil sample (Ayvalık cv.) was characterized by linoleic/linolenic ratio (L-LN). Also, stearic, palmitic, and SFA (SF) were identified in the classification of Havran (HV), Edremit (ED), Ezine (EZ), and Altınova (AL) districts covering the most part of the North Aegean zone growing domestic Ayvalık olive cultivar.

Also the Aegean monocultivar (Ayvallk and Memecik cv.) virgin olive oils from the North and South zones were classified by chemometric methods (PCA and HCA) according to the FA profile calculated on the basis of TAG. The classification based on estimated FA components like their TAG data results (Fig. 4) were divided into main two groups-North Aegean (Ayvalık cultivar) and South Aegean (Memecik cultivar) (Fig. 7). 


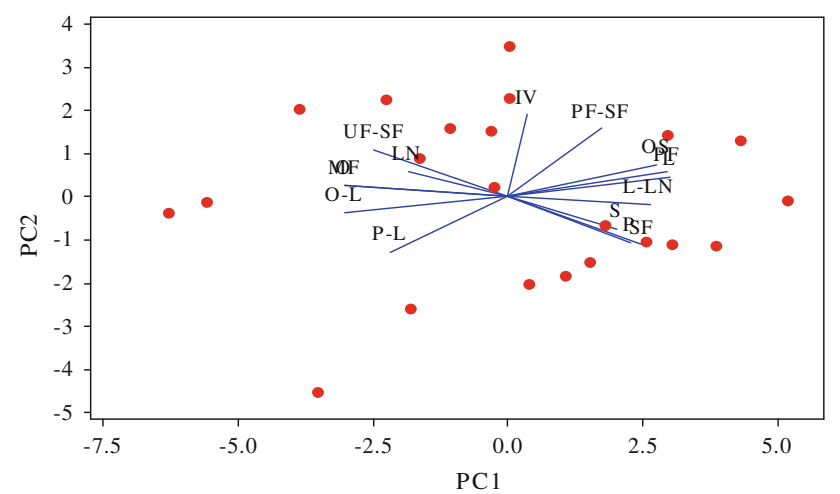

Fig. 6 Biplot of scores (left) and loadings (right) for the first three PC (PC1, PC2, and PC3) for the Turkish virgin olive oil samples from the Aegean region based on their fatty acid profiles (the first three PC which account for $98 \%$ of the variability in the data)

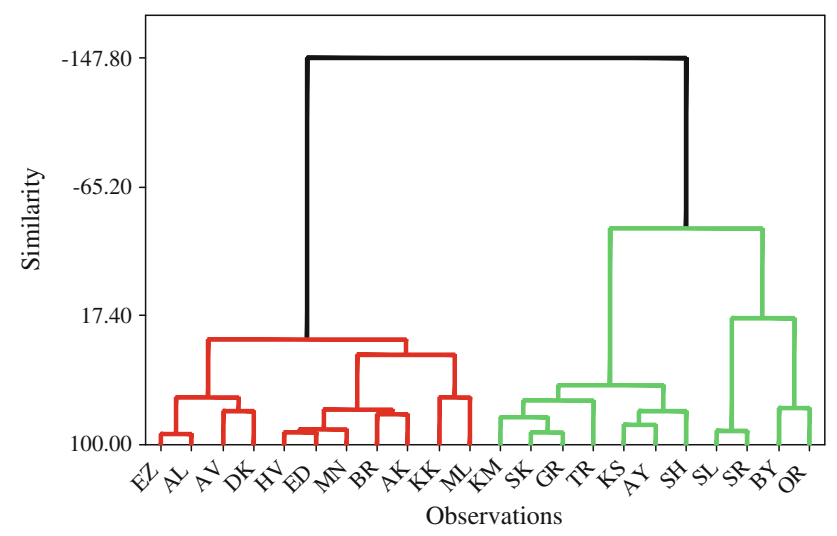

Fig. 7 Dendogram of scores of first three PC (PC1, PC2, PC3) from the hierarchical cluster analysis (HCA) for the Turkish virgin olive oil samples from the Aegean region based on their fatty profiles (the first three PC which account for $98 \%$ of the variability in the data)

As can seen in Fig. 7, group 1 (North Aegean zone including Ayvallk olive cultivar) is made up of three subgroups and they include Ezine (EZ), Altinova (AL), and Ayvalık (AV) (subgroup 1); Havran (HV), Edremit (ED), Menemen (MN), Burhaniye (BR), and Akhisar (AK) (subgroup 2) (North Aegan samples or Ayvalık cultivar); and Köşk (KK) and Milas (ML) (subgroup 3 [South Aegan samples or Memecik cultivar]) according to the locations. Group 2 comprised three subgroups covering the Memecik olive cultivar and the group two includes Kemalpaşa (KM), Söke (SK), Germencik (GR), Tire (TR), Kuşadası (KS), Aydın (AY), and Sultanhisar (SH) (subgroup 1); Selçuk (SL) and Şirince (ŞR) (subgroup 2); and Bayındır (BY) and Ortaklar (OR) (subgroup 3).

The chemometric analysis results indicated that the Turkish monocultivar oils from the two (North and South) subzones of the Aegean region would correctly be classified for olive cultivar or growing area using the main glyceridic structure of oils like TAG and FA profiles. The Ayvalık (North Aegean zone) and Memecik (South Aegean zone) oils from different growing regions could be differentiated on the basis of their TAG profiles with PCA and HCA results. This study is a first step towards the subjective characterization and classification of economically important areas in monocultivar (especially Ayvalık and Memecik cv.) oil production for utilization in the Turkish olive oil industry.

Acknowledgments The authors wish to thank Mr. Metin Aydogdu (Agric. Eng., Department of Geographical Information Systems, Ministry Agriculture and Rural Affairs, Ankara) for the map of the Aegean Region, Turkey.

\section{References}

1. Öztürk F, Yalçın M, Dıraman H (2009) An overview on the olive oil economy of Turkey. Electron J Food Technol 12:37-53

2. Turkish Patent Institute (2013) http://www.tpe.gov.tr/portal/ default2.jsp?sayfa=431. Accessed 07 Aug 2013

3. Montealegre C, Mariane Alegre ML, Garcia-Ruiz C (2010) Traceability markers to the botanical origin in olive oils. J Agric Food Chem 58:28-38

4. Tsimidou M, Macrae R, Wilson I (1987) Authentication of virgin olive oils using principal component analysis of triglyceride and fatty acid profiles: part I-classification of Greek olive oils. Food Chem 25:227-239

5. Aparacio R, Luna G (2002) Characterisation of monovarietial virgin olive oils. Eur J Lipid Sci Technol 104:614-627

6. Aparacio R, Aparacio-Ruiz R (2000) Authentication of vegetable oils by chromatographic techniques. J Chromatogr A 881:93-104

7. Aparicio R (1999) Characterization: mathematical procedures for chemical analysis. In: Aparicio R, Harwood J (eds) Handbook of olive oil: analysis and properties. Springer-Verlag, New York, pp 285-354

8. Stefanoudaki E, Kotsifaki F, Koutsaftakis A (1997) The potential of HPLC triglyceride fort the classification of Cretan olive oils. Food Chem 60:425-432

9. Ollivier D, Artaud J, Pinatel C, Durbec JP, Guèrère M (2003) Triacylglycerol and fatty acid compositions of French virgin olive oils: characterisation by chemometrics. J Agric Food Chem 51:5723-5731

10. Ollivier D, Artaud J, Pinatel C, Durbec JP, Guèrère M (2006) Differentation of French virgin olive oil RDO's by sensory characteristics, fatty acid and triacylglicerol compositions and chemometrics. Food Chem 97:382-393

11. Jimenez-Marquez A, Beltran-Maza G (2003) Applicacion de la differancial de barrido (CDB) en la caracterization del aceite de oliva virgen. Grasas Aceites 54:403-409

12. Aranda F, Gomez-Alanso S, Rivera del Alamo RM, Salvador MD, Fregapane G (2004) Triglyceride total and 2-position fatty acid composition of Cornicobra virgin olive oil: comparision with other Spanish cultivars. Food Chem 86:485-492

13. Casas Sanchez J, Oserio Bueno E, Montano Garcia AM, Martinez Cano M (2003) Estudio del contenido en acidos grasos de aceites monovarietales elaborades a partir de aceitunas producidas en la region extremenă. Grasas Aceites 54:371-377

14. Casas JS, Gordillo CM, Bueno EO, Expósito JM, Mendoza MF, Hierro TA, González LG, Cano MM (2009) Characteristics of virgin olive oils from the olive zone of Extremadura (Spain), and an approximation to their varietal origin. J Am Oil Chem Soc 86:933-940 
15. Ben Miled DD, Smaoui A, Zarrouk M, Cherif A (2000) Do extraction procedures affect olive oil quality and stability? Biochem Soc Trans 28(6):929-933

16. Haddada MF, Mania H, Oueslati I, Daoud D, Sánchez J, Osorio E, Zarrouk M (2007) Fatty acid, triacylglycerol, and phytosterol composition in six Tunisian olive varieties. J Agric Food Chem 55:0941-10946

17. Ünal MK, Gültekin G (1996) Triglyceride composition of Turkish virgin olive oils. In: Köseoğlu SS, Rhee KC, Wilson RF (eds) Advances in oils and fats. Antioxidants and oilseed byproducts volume II. Proceedings of the world conference on oilseed and edible oils processing, Istanbul, October 6-10 1996. AOCS, Champaign, pp 201-204

18. Diraman H, Çam M, Özder Y (2009) Classification of virgin olive oils of domestic and foreign origin based on their triacylgycerol profiles with chemometric methods. J Food 34(3):157-164

19. Ilyasoglu H, Ozcelik B (2011) Determination of seasonal changes in olive oil by using differential scanning calorimetry heating thermogram. J Am Oil Chem Soc 88:907-913

20. Canözer Ö (1991) The catalogue for standard olive varieties. Turkish Ministry of Agriculture and Rural Affairs, Publication No 334, Series 16. TUGEM, Ankara

21. Diraman H, Dibeklioğlu H (2009) Characterization of Turkish virgin olive oils produced from early harvest olives. J Am Oil Chem Soc 86:663-674
22. European Union Commission Regulation 2568/91 (1991) The characteristics of olive oil and olive-residue oil and on the relevant methods of analysis. Off J Eur Commun L 248:1-83

23. Byrdwell WC, Emken EA, Neff WE, Adlof RO (1996) Quantitative analysis of triglycerides using atmospheric pressure chemical ionization-mass spectrometry. Lipids 31:919-935

24. Kamal, Eldin A (2006) Effect of fatty acids and tocopherols on the oxidative stability of vegetable oils. Eur J Lipid Sci Tech 58:1051-1061

25. Cert A, Alba J, León-Camacho M, Moreda W, Carmen PèrezCamino M (1996) Effects of talc addition and operating mode on the quality and oxidative stability of virgin olive oils obtained by centrifugation. J Agric Food Chem 44:3930-3934

26. Özdemir D, Öztürk B (2007) Near infrared spectroscopic determination of olive oil adulteration with sunflower and corn oil. J Food Drug Anal 15:40-47

27. Kiritsakis AK (1998) Olive oil: from the tree to the table. Food \& Nutrition, Trumbull

28. Christopoulou E, Lazaraki M, Komaitis M, Kaselimis K (2004) Effectiveness of determinations of fatty acids for the detection of adulteration of olive oils with vegetable oils. Food Chem 84:463-474

29. Flor RV, Hecking LT, Martin BD (1993) Development of highperformance liquid chromatography criteria for determination of grades of commercial olive oils. Olivae 48:37-42 